\title{
Long-Distance Person Travel: A Cluster-Based Approach
}

Mina Hassanvand ${ }^{1}$ (1)

${ }^{1}$ Civil Engineering, University of Calgary

Keywords: cluster analysis, fuzzy c-means, k-means, agglomerative hierarchical clustering, travel behaviour, travel modelling, long-distance person travel

\section{Transport Findings}

\begin{abstract}
Many long-distance person trips (LDPT) modelling efforts fail to accurately represent trips using traditional segmentation approaches. Thus, a clustering approach was used herein to segment an intra-provincial trips data set. The trips' segments found were short economical getaways (36\%), same-day shopping (16\%), personal business (14\%), visiting friends/relatives (10\%), business/casino trips (10\%), young adults playing team sports (6\%), same-day trips of snow/ festival loving young families with kids (3\%), costly cottage/camping trips (3\%), seniors with medical appointments (2\%), and multiple city visitors (1\%). The existence of clusters and associated activities shows what segmentation approaches modern models should follow.
\end{abstract}

The analysis of travel demand often includes the partitioning of the demand into "market segments" seeking to separate these influences into groups. As demonstrated in (Larse 2010; Travel Demand Modelling 2016; Limtanakool, Dijst, and Schwanen 2006; Bhat 1997b; Koppelman and Sethi 2000; Mandel, Gaudry, and Rothengatter 1997; Ben-Akiva and Lerman 1987; Wardman, Toner, and Whelan 1997; LaMondia, Bhat, and Hensher 2008; Carlsson 1999; Hensher 1991; Morrison and Winston 1985; Hassanvand 2020), the development of such models includes substantial effort that encompasses enormous revalidation work, which has been reduced with the aid of advanced computer technology. However, there still exists a gap in model design that arise from failure to segment markets.

This paper defines travel alternatives made by market segments with the aim of optimizing the selection of descriptive variables and strengthening the explanatory power of the model. Nearly all long-distance person trips (LDPT) models (Federal Highway Administration 2015; Golob 2001; Kizielewicz et al. 2017; Bhat 1997a; Golob and Hensher 1998; Badoe and Miller 1998; Lieberman et al. 2001) developed in various countries are based not on empirical procedures but rather by educated guesses to describe the travel market variables. This research transforms the approach to traditional segmentations using computer science approaches for network-based data that stem from fuzzy logic (Zadeh 1965). Such approaches are based on grouping of data points by examining their proximity (e.g. Euclidean distance) to one another. This is essential as LDPT is not merely the longer version of shortdistance daily trips. While fuzzy-neuro models have been used in transit and some short-distance models (Kumar, Sarkar, and Madhu 2013; Sarkar 2012; Tharwat 2014; Roxas 2016; Yaldi et al, n.d.; Gite 2013), they have not been used in LDPT - excluding goods movement, trucking, or air travel. 
Table 1: Clustering Steps

\begin{tabular}{ll}
\hline Clustering Steps & Description \\
\hline Step 1 & Select an initial partition $\mathrm{K}(\mathrm{C} 1, \ldots, \mathrm{Ck})$ \\
Step 2 & Calculate centroid $\quad w_{i}=\left(\frac{1}{k}\right) \sum_{j=1}^{k i}\left(w_{i j}\right) \quad$ for $\mathrm{i}=1, \ldots, \mathrm{k}$ \\
Step 3.1 & For each $\mathrm{w}_{\mathrm{i}}$ reassign $\mathrm{w}_{\mathrm{i}}$ to its closes centroid $\mathrm{C}_{\mathrm{t}}$ if $\left\|\mathrm{w}_{\mathrm{i}}-\mathrm{w}_{\mathrm{t}}\right\|<=\left\|\mathrm{w}_{\mathrm{i}}-\mathrm{w}_{\mathrm{j}}\right\|$ for all $\mathrm{j}=1, \ldots, \mathrm{k}, \mathrm{j} !=\mathrm{s}$ \\
Step 3.2 & Recalculate centroids for clusters $\mathrm{C}_{\mathrm{s}}$ and $\mathrm{C}_{\mathrm{t}}$ \\
Step 4 & In cluster membership is stabalized then stop or else go to Step 3 \\
\hline
\end{tabular}

Table 1: Clustering Steps

\section{METHODS AND DATA}

Clustering is a statistical tool used in pattern recognition and machine learning to find similar groups in seemingly dissimilar network-based datasets (e.g. transport data). Objects in a cluster/class share many characteristics but are very dissimilar to objects not belonging to that particular cluster (Punj and Stewart 1983). In most of the classification works (Milligan 1996; Posse 1998; Everitt, Landau, and Leese 2001), considerable number of algorithms belong to two major types of clustering used here namely Hierarchical and Partitional. The former is based on finding clusters hierarchy using a criterion and producing a dendrogram. The latter is partitioning the data based on minimization of an objective function such as the squared error function (Kaufman and Rousseeuw 1990; Bezdek 1974):

$J=\sum_{j=1}^{k} \quad \sum_{i=1}^{n}\left\|x_{i}^{(j)}-c_{j}\right\|^{2}$

Where $\left\|\mathbf{x}_{\mathbf{i}}^{(\mathbf{j})}-\mathbf{c}_{\mathbf{j}}\right\|^{\mathbf{2}}$ is the distance between a data item $\mathbf{x}_{\mathbf{i}}^{(\mathbf{j})}$ and a centre point $\mathbf{c}_{\mathbf{j}}$.

One type of partitional clustering, with steps shown in Table 1, is called the kmeans approach as a specific form of the more general fuzzy c-means clustering that minimizes a similar objective function [34]:

The uniqueness of this work lies partly in the essential three-step cluster validity checks which are often ignored in many clustering themed studies (Dunn 1974; Zaki and Meira, Jr 2014):

1. Cluster tendency checks: which is a measure of clusterability of a data set considering that algorithms such as k-mean unquestioningly find some clusters in a data set regardless. Thus, to ensure the data is actually clusterable, one must examine it for its clustering tendency using indices such as the Hopkins statistics prior to any clustering practices. 
2. Cluster stability checks: is the practice of clustering randomly generated data sets out of the original data and data belonging to other years/locations in order to examine if the resulting clusters are persistent and show up each time. Also, clustering the data set using fuzzy c-means provides an additional check on the existence/lack of potential outliers and acts as a precautionary measure against modeldependency of results.

3. Cluster validity: consists of three tests namely External (one-way ANOVA, Post-hoc Bonferroni, and Logistic Regression), Internal (Beta-CV index), and Relative (Elbow method). Other tests include variables' correlation checks, F-tests, Grubb's test of outliers, Ward's (AHC) dendrogram analyses and stopping rules comparison of a large Duda-Hart Je(2)/Je(1) index with a small Pseudo T-tests and a large Calinski-Harabasz Pseudo-F indices for detection of number of clusters (Everitt, Landau, and Leese 2001).

The publicly available standardized and weighted 2017 Travel Survey of Residents of Canada (TSRC) data set - including 14064 Province of Alberta $(\mathrm{AB})$ residents, $4167 \mathrm{AB}$ to $\mathrm{AB}$ trips, and 6128 nights travelled - is examined and compared with 2016 and 2015 data. TSRC is a supplement of the Canadian Labour Force Survey (LFS) (Statistics Canada 2017b, 2017a) after which TSRC questions are asked of a random $18+$ household $(\mathrm{HH})$ member regarding any one-way $40+\mathrm{km}$ trips from home finished in the previous month (same-day/overnight) plus any overnight trips ended two months before regardless of distance. Figure 1 shows trip counts by distance/purpose followed by variables' list in Table 2 . Analysis is based on 100 variables with minimal correlations from socio-demographic factors to places visited and 37 different activities divided into same-day/overnight.

\section{FINDINGS}

Table 3 describes 10 clusters found in the 2017 data set followed by Figure $\underline{2}$ which is a $3 \mathrm{D}$ representation of clusters' center points across some of the most important dimensions (for brevity). Figure 3 represents a dendrogram of classes hierarchy found through (AHC) clustering.

Examinations revealed the data possess a natural structure with 10 clusters at $68 \%$ confidence level. Such results are consistent with other literature findings for LD trips (Future Foundation 2015; Birley and Westhead 1990; Mooi and Sarstedt 2011). For example, trips done for pleasure have consistently been found to belong to mostly the top two categories of LDPT. The second largest cluster is representative of individual adults from the same $\mathrm{HH}$ who travel in smaller groups with no kids. Their purpose is mainly same-day trips of shopping with moderate levels of spending with activities such as walking. This finding is novel and could be a characteristic of the Province of Alberta, in that malls and shopping centres such as Banff, Lake Louise, West Edmonton 


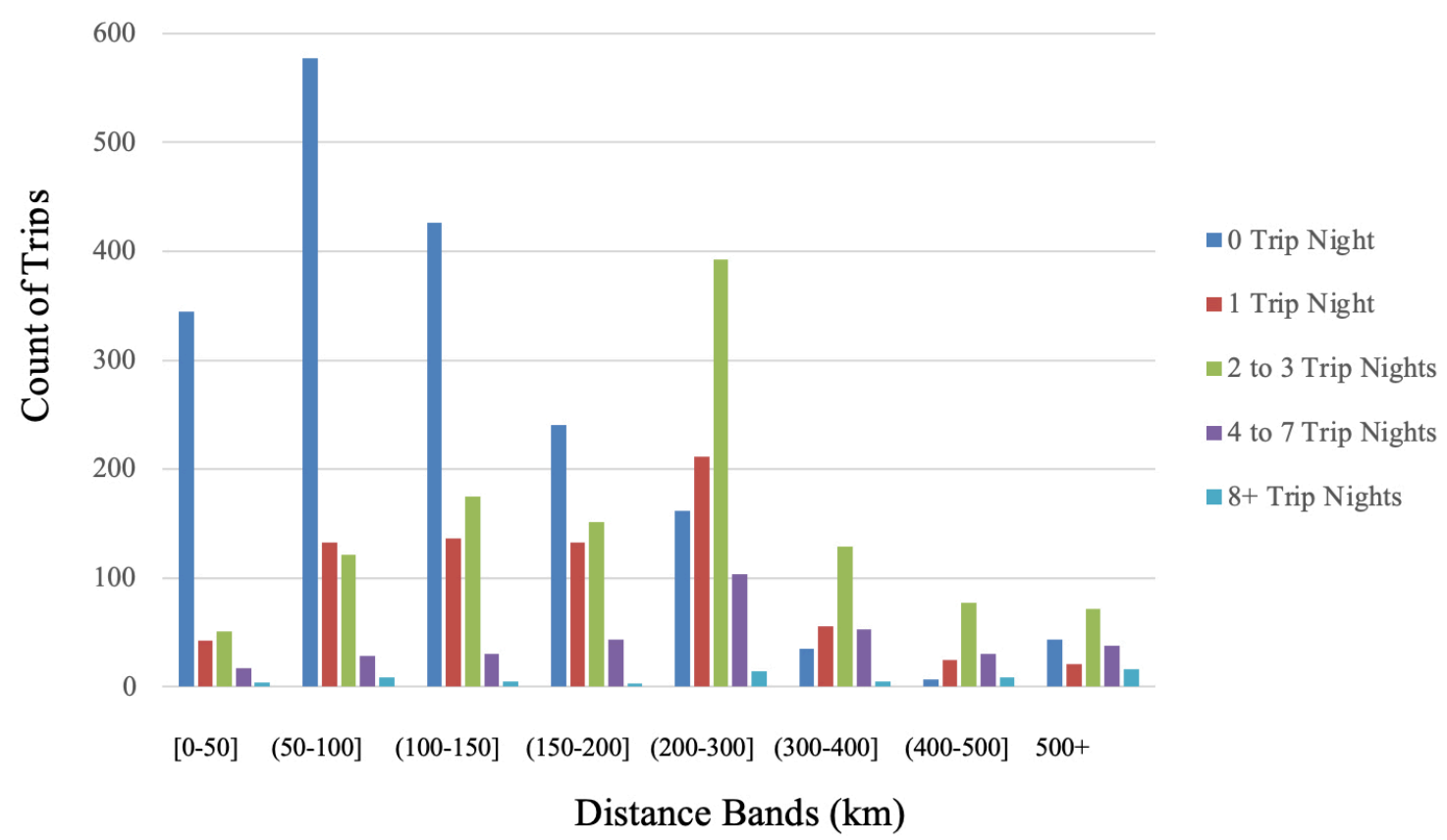

Figure 1: Count of Trips by Distance and Canadian Nights Away for 2017 (TSRC) 4167 (AB) to (AB) Trips

mall, or other shopping avenues are also long-distance traveller attractors. The existence of such clusters demonstrates how traditional LDPT trips segmentation through "guessing variables and rechecking" are obsolete and would need to be enhanced using comprehensive clustering approaches targeted for network-based data to better represent the overall LDPT market while relying less on conjecture and assumptions.

Submitted: September 20, 2020, Accepted: September 20, 2020 


\begin{tabular}{|c|c|c|c|}
\hline \# Name & Label & Type & Question \\
\hline 1 TR_G08 & Household members 18 or older who went on the trip - Capped & continuous & Number of household members 18 years of age and over on trip - Capped. \\
\hline 2 TR_D11 & Number of identical trips - capped & continuous & How many? (Identical trips). \\
\hline 3 TS TOTAL & Total amount spent on all spending & continuous & Total amount spent on all spending, including amount extracted from travel packages. \\
\hline 4 DIST2 & Distance of trip - farthest location & continuous & one way distance in $\mathrm{km}$ travelled to the farthest destination location \\
\hline 5 TRIP_CNT & Total number of trip records & continuous & Total number of trip records \\
\hline 6 TP_D01 & Total number of people in travel party - Grouped & continuous & Total number of people in travel party - Grouped. \\
\hline 7 T_G0802 & Household members who went on the trip - Capped & continuous & Household members who went on trip- Capped. \\
\hline $8 \mathrm{TP}$ G02 & Household members under 18 who went on the trip - Capped & continuous & Number of household members under 18 years of age on trip - Capped. \\
\hline 9 AGE_GR2 & Age group of the respondent - Grouped & discrete & age of the $18+$ random respondent to TSRC \\
\hline $10 \mathrm{SEX}^{-}$ & Sex of respondent & discrete & sex of the $18+$ random respondent to TSRC \\
\hline 11 EDLEVGR & Education level of respondent - Grouped & discrete & education level of the $18+$ random respondent to TSRC \\
\hline 12 LFSSTATG & Labour force status - Grouped & discrete & employed or unemployed status of the $18+$ random respondent to TSRC \\
\hline 13 MDDPLFL & Province of trip Destination & discrete & residency Province of the $18+$ random respondent to TSRC \\
\hline 14 INCOMGR2 & Household income - 4 groups & discrete & Household income - 4 groups. \\
\hline 15 CANNITE & Total number of nights in Canada during the trip & discrete & Total number of nights on the trip spent in Canada. \\
\hline 16 REFYEAR & Reference year & discrete & Reference year \\
\hline 17 REFMONTH & Reference month & discrete & Reference month \\
\hline 18 TRIPTYPE & Type of trip & discrete & Type of trip. \\
\hline 19 MRDTRIP3 & Main reason for the trip - 7 categories & discrete & Main reason for the trip - 7 categories. \\
\hline 20 ORCPROVT & Province of trip origin & discrete & Province of trip origin. \\
\hline 21 TMDTYPE2 & Main mode of transportation used on the trip & discrete & Main mode of transportation used on the trip. \\
\hline 22 AT_Q01X & Activity - Attend an aboriginal event & discrete & On this trip did you attend an aboriginal event (pow wow, performance, other)? \\
\hline 23 AT_Q01H & Activity - Go to a beach & discrete & On this trip did you go to a beach? \\
\hline 24 AT_Q01J & Activity - Go boating & discrete & On this trip did you go boating? \\
\hline $25 \mathrm{AT}^{-} \mathrm{Q} 01 \mathrm{G}$ & Activity - Go wildlife viewing or bird watching & discrete & On this trip did you go wildlife viewing or bird watching? \\
\hline 26 AT_Q01I & Activity - Go camping & discrete & On this trip did you go camping? \\
\hline 27 AT_Q010 & Activity - Go canoeing or kayaking & discrete & On this trip did you go canoeing or kayaking? \\
\hline $28 \mathrm{AT}$ Q01P & Activity - Go to a casino & discrete & On this trip did you go to a casino? \\
\hline 29 AT_Q01N & Activity - Go cycling & discrete & On this trip did you go cycling? \\
\hline 30 AT_Q01Q & Activity - Attend a festival or fair & discrete & On this trip did you go to a fair or attend a festival? \\
\hline $31 \mathrm{AT}_{-} \mathrm{Q} 01 \mathrm{~K}$ & Activity - Go fishing & discrete & On this trip did you go fishing? \\
\hline 32 AT_Q01M & Activity - Go golfing & discrete & On this trip did you go golfing? \\
\hline 33 AT_Q01F & Activity - Go hiking or backpacking & discrete & On this trip did you go backpacking or hiking? \\
\hline 34 AT_Q01B & Activity - Visit a historic site & discrete & On this trip did you visit a historic site? \\
\hline 35 AT_Q01L & Activity - Go hunting & discrete & On this trip did you go hunting? \\
\hline 36 AT_Q01C & Activity - Visit a museum or art gallery & discrete & On this trip did you go to an art gallery or visit a museum? \\
\hline 37 AT Q01A & Activity - Visit a national/ provincial or nature park & discrete & On this trip did provincial or nature park? \\
\hline 38 AT_Q01D & Activity - Attend a performance & discrete & On this trip did you attend a performance such as a play or concert? \\
\hline 39 AT_Q01V & Activity - Go cross country skiing or snowshoeing & discrete & On this trip did you go cross country skiing or snowshoeing? \\
\hline $40 \mathrm{AT}_{-}^{-} 01 \mathrm{~W}$ & Activity - Go snowmobiling & discrete & On this trip did you go snowmobiling? \\
\hline 41 AT_Q01E & Activity - Attend a sports event as a spectator & discrete & On this trip did you attend a sports event as a spectator? \\
\hline 42 AT_Q01T & Activity - Play individual or team sports & discrete & On this trip did you play individual or team sports? \\
\hline 43 AT_Q01R & Activity - Visit a theme or amusement park & discrete & On this trip did you visit a theme or amusement park? \\
\hline $44 \mathrm{AT}_{-}^{-} \mathrm{Q} 01 \mathrm{~S}$ & Activity - Visit a zoo or aquarium & discrete & On this trip did you visit a zoo or aquarium? \\
\hline 45 AT_Q01Z & Activity - Shop (include all markets) & discrete & On this trip did you go shopping (include all markets)? \\
\hline 46 AT_Q01U & Activity - Go downhill skiing or snowboarding & discrete & On this trip did you go downhill skiing or snowboarding? \\
\hline 47 AT_Q01AA & Activity - Attend a business/ other meeting & discrete & On this trip did you attend a business/ other meeting/conference/seminar? \\
\hline $48 \mathrm{AT} Q 01 \mathrm{AB}$ & Activity - Go to a medical/ dental appointment & discrete & On this trip did you medical/dental appointments? \\
\hline 49 AT_Q01AC & Activity - Sightsee & discrete & On this trip did you go for sightseeing? \\
\hline 50 AT_Q01AD & Activity - Go to the movies & discrete & On this trip did you go to movies? \\
\hline $51 \mathrm{AT} Q 01 \mathrm{AE}$ & Activity - Dine out/go to restaurant/bar/club & discrete & On this trip did you restaurant/bar/club? \\
\hline $52 \mathrm{AT} \_\mathrm{Q} 01 \mathrm{AF}$ & Activity - ATV (quad, 4X4) & discrete & ATV (quad, 4X4)? \\
\hline 53 AT_Q01AG & Activity - Did not do any activities & discrete & no activities? \\
\hline 54 AT_Q01AH & Activity - Other activity & discrete & other activities? \\
\hline 55 AT_Q02 & Activity - Most important - Same day trip & discrete & most important activity for same-day trips? \\
\hline
\end{tabular}
discrete reunion or dinner, babysitting, etc.)?

Table 2: List of Variables 
Represents trips (with frequency of two) made by most likely University educated adults in $\begin{array}{ll}\text { Short Economical } & \text { smaller groups (mostly one traveller or potentially only one other partner) not from the same } \\ & \text { HH going on short (same-day) getaways of about } 100 \mathrm{~km} \text { in private cars for pleasure purposes }\end{array}$ Getaways and having low spending amounts (less than \$100) with potential overnight activities such as skiing and same-day activities such as cycling, hiking, and visiting parks.

Trips (with frequency of two) consisting of smaller groups (two travellers) of adults from the Same-day Shopping same HH travelling with no kids on short trips (same-day) with moderate levels of spending (about $\$ 150$ ) and travelling shorter distances (about $100 \mathrm{~km}$ ) in mostly private cars.

Represents trips (with frequency of two) characterized by individual older adults travelling Personal Business mostly alone or with only one other traveller for longer distances (about $300 \mathrm{~km}$ ) by air and Trips taxi for long number of nights (about one week) with no kids and moderate spending (about $\$ 250$ ) and having "other" types of activities. Trips (with frequency of one) consisting of larger groups (about 4) mostly from the same $\mathrm{HH}$
with older kids travelling shorter distances (about $100 \mathrm{~km}$ ) on trips of about three nights in private cars with moderate spending (about $\$ 150$ ) for the purpose of visiting friends and relatives and having not many activities.

Represents trips (with frequency of one) consisting of younger adults (with mostly low incomes in groups of about two) travelling by air, bus, and/or rental cars for longer distances (over $250 \mathrm{~km}$ ) and about two nights away and spending around \$200 visiting casinos while on the trip, playing sports, skiing, or being a sports spectator most likely alongside business partners. The fact that such trips are mostly taken by young adults confirms the findings of [38] stating that $45 \%$ of most business trips are taken by Millennials and younger adults.

Trips (with frequency of two) consisting of younger parents with lower levels of income from the same $\mathrm{HH}$ (with groups of three travellers) going on shorter (about $100 \mathrm{~km}$ ) low budget

Young Families with trips in private cars (under \$100) for about two nights with kids and participating in snow Children going to related activities in the winter time and visiting zoo, parks, and festivals in the warmer Seasonal Events months. These results confirm the findings of [39] that states events have now become one of the main attractors of travellers as many seek a more planned trip as well as a cultural experience in the process.

Represents trips (with frequency of one) consisting of non-adult members (in groups of three Team Sport Players or more) from the same household with high school education and low incomes going on overnight trips (about a week) in buses and most likely participating in team sports and spending about $\$ 200$ having travelled longer distances of about $300 \mathrm{kms}$.

Represents trips (with frequency of two) consisting of mixed generation of adults in groups of

Costly $\begin{array}{ll}\text { Cottage/Camping } & \text { two from different } \mathrm{HHs} \text { with high levels of spending (over } \$ 400 \text { ) and lower kilometers } \\ \text { travelled (about } 150 \mathrm{~km} \text { ) on cottage, camping, or boating trips of about two nights in private }\end{array}$ cars.

Trips (with frequency of one) consisting of low income low educated seniors travelling in Seniors with Medical groups of about three or in pairs on same-day or overnight shorter trips (about $100 \mathrm{~km}$ ) with Appointments private cars or buses with light levels of spending (about \$80) and having no or little activities such as shopping and going to medical appointments.

This grouprep reprsents high educated outdoorsy visitors (in groups of three or more) on Multiple City higher budget trips (about \$500) involving visiting more than two locations along the way

Visitors higher budget trips (about $\$ 500$ ) involving visiting more than two locations along the way
having travelled about $200 \mathrm{~km}$ and spent two nights using travel modes such as RVs and

Table 3: Clusters Found in the 2017 (TSRC) (AB) to (AB) Trips at 68\% Confidence Level 

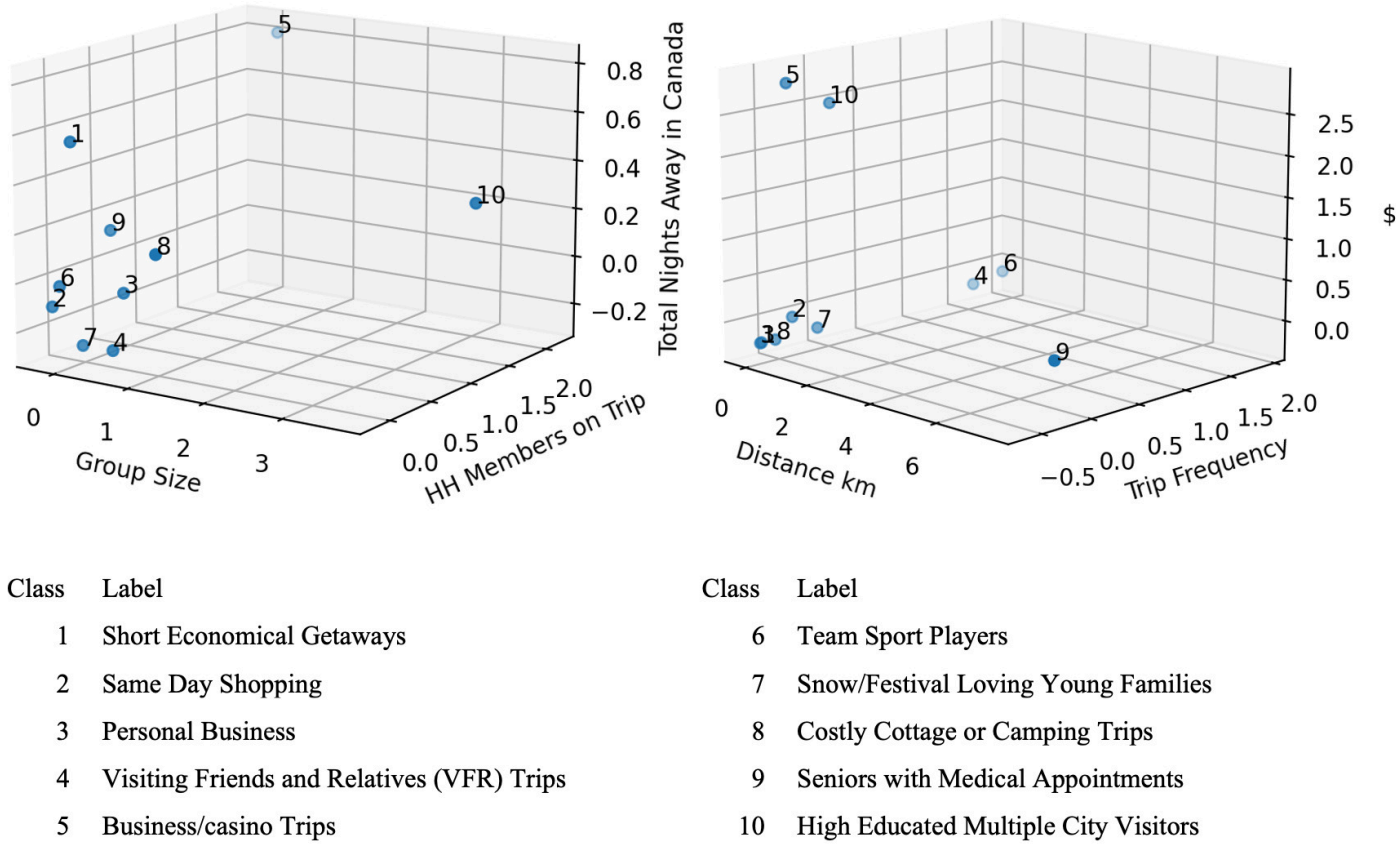

1 Short Economical Getaways

2 Same Day Shopping

3 Personal Business

4 Visiting Friends and Relatives (VFR) Trips

5 Business/casino Trips

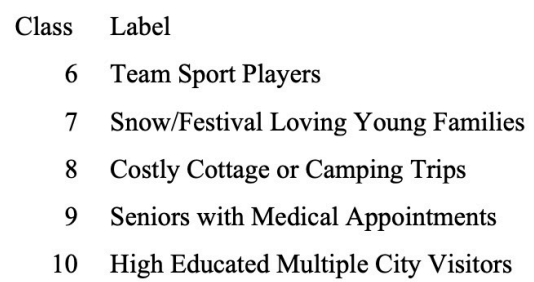

Figure 2: 3D Representation of 10 Clusters Across a few Key Dimensions: Household (HH) Members on the Trip, Travelling Group Size, Total Nights Away from home while on Trip, One-way Distance from Home in km, Trips Frequency, Total Amount of Spending while on Trip in 2017 \$CAD

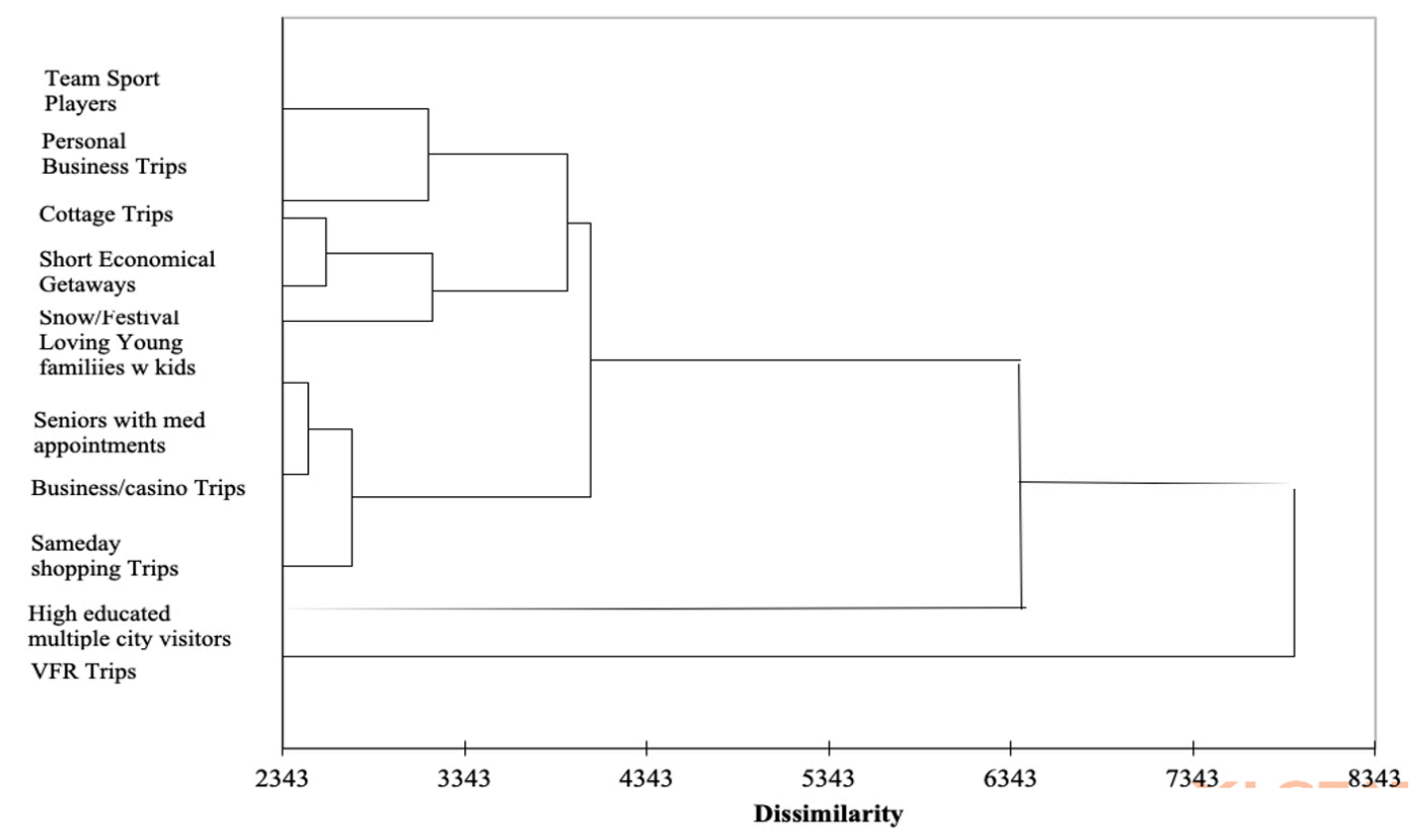

Figure 3: 2017 (TSRC) (AB) to (AB) Trips (AHC) Ward's Dendrogram

This is an open-access article distributed under the terms of the Creative Commons Attribution 4.0 International License (CCBY-SA-4.0). View this license's legal deed at https://creativecommons.org/ licenses/by-sa/4.0 and legal code at https://creativecommons.org/licenses/by-sa/4.0/legalcode for more information. 


\section{REFERENCES}

Badoe, Daniel A., and Eric J. Miller. 1998. "An Automatic Segmentation Procedure for Studying Variations in Mode Choice Behaviour." Journal of Advanced Transportation 32 (2): 190-215. https://doi.org/10.1002/atr.5670320205.

Ben-Akiva, M., and S. Lerman. 1987. Discrete Choice Analysis: Theory and Application to Travel Demand. Cambridge, MA: MIT Press.

Bezdek, J. C. 1974. "Numerical Taxonomy with Fuzzy Sets.” Journal of Mathematical Biology 1 (1): 57-71. https://doi.org/10.1007/bf02339490.

Bhat, C. R. 1997a. "An Endogenous Segmentation Mode Choice Model with an Application to Intercity Travel.” Transportation Science 31 (1): 34-48. https://doi.org/10.1287/trsc.31.1.34.

_- _. 1997b. "Covariance Heterogeneity in Nested Logit Models: Econometric Structure and Application to Intercity Travel." Transportation Research Part B: Methodological 31 (1): 11-21. https://doi.org/10.1016/s0191-2615(96)00018-5.

Birley, S., and P. Westhead. 1990. "Growth and Performance Contrasts between 'Types' of Small Firms.” Strategic Management Journal 11 (7): 535-57.

Carlsson, F. 1999. "Private vs. Business and Rail vs. Air Passengers: Willingness to Pay for Transport Attributes." In Department of Economics of Goteborg University, Working Paper in Economics No, 14. https://gupea.ub.gu.se/handle/2077/2679.

Dunn, J. C. 1974. "Some Recent Investigations of a New Fuzzy Partitioning Algorithm and Its Application to Pattern Classification Problems." Journal of Cybernetics 4 (2): 1-15. https://doi.org/ $\underline{10.1080 / 01969727408546062 .}$.

Everitt, B. S., S. Landau, and M. Leese. 2001. Cluster Analysis. 4th ed. Arnold, London.

Federal Highway Administration. 2015. "Foundational Knowledge to Support a Long-Distance Passenger Travel Demand Modeling Framework Part A: Final Report.” http://rsginc.com/files/ publications/Long\%20Distance\%20Model\%20Framework\%20Final\%20Report.pdf.

Future Foundation. 2015. “Understanding Tomorrow's Traveller.” http://www.amadeus.com/ web/binaries/blobs/378/139/amadeus-future-traveller-tribes-2030-report.pdf.

Gite, Akhil V. 2013. “ANFIS Controller and Its Application”.” International Journal of Engineering Research and Technology 2 (ue 2).

Golob, T. F. 2001. "Joint Models of Attitudes and Behavior in Evaluation of the San Diego I-15 Congestion Pricing Project." Transportation Research Part A: Policy and Practice 35 (6): 495-514. https://doi.org/10.1016/s0965-8564(00)00004-5.

Golob, T. F., and D. A. Hensher. 1998. "Greenhouse Gas Emissions and Australian Commuters' Attitudes and Behavior Concerning Abatement Policies and Personal Involvement." Transportation Research Part D: Transport and Environment 3 (1): 1-18. https://doi.org/10.1016/ s1361-9209(97)00006-0.

Hassanvand, M. 2020. "Adjusting Logit Model Estimation Results Obtained with Stated Preference Data." International Journal of Scientific E'Engineering Research Volume 11 (June 6). https://www.ijser.org/onlineResearchPaperViewer.aspx?Adjusting-Logit-Model-EstimationResults-Obtained-with-Stated-Preference-Data.pdf.

Hensher, D.A. 1991. "Efficient Estimation of Hierarchical Logit Mode Choice Models." Proceedings of the Japanese Society of Civil Engineering 425 (IV-14): 17-28.

http://library.jsce.or.jp/jsce/open/00037/425/425-120617.pdf. 
Kaufman, Leonard, and Peter J. Rousseeuw, eds. 1990. Finding Groups in Data. Wiley Series in Probability and Statistics. New York: John Wiley \& Sons, Inc. https://doi.org/10.1002/ $\underline{9780470316801 .}$.

Kizielewicz, Joanna, Anntti Haahti, Tihomir Luković, and Daniela Gračan. 2017. “The Segmentation of the Demand for Ferry Travel - a Case Study of Stena Line." Economic ResearchEkonomska Istraživanja 30 (1): 1003-20. https://doi.org/10.1080/1331677x.2017.1314789.

Koppelman, F.S., and V. Sethi. 2000. "Incorporating Complex Substitution Patterns and Variance Scaling in Long-Distance Travel Choice Behavior.” Paper presented at the 9th International Association on Travel Behavior Research Conference, July 2-7, 2000, Goldcoast, Gueenslan.

Kumar, Mukesh, Pradip Sarkar, and Errampalli Madhu. 2013. "Development Fuzzy Logic-Based Model Mode Choice Model Considering Various Public Transport Policy.” IJTTE 3 (4): 408-25. https://doi.org/10.7708/ijtte.2013.3(4).05.

LaMondia, J., C. Bhat, and D. Hensher. 2008. "An Annual Time Use Model for Domestic Vacation Travel." Journal of Choice Modeling 1 (1): 70-97. http://www.jocm.org.uk/index.php/JOCM/ article/viewFile/38/15.

Larse, Nynne. 2010. Market Segmentation - A Framework for Determining the Right Target Customers. Published Thesis. Aarhus School of Business.

Lieberman, William, Dave Schumacher, Alan Hoffman, and Christopher Wornum. 2001.

"Creating a New Century of Transit Opportunity: Strategic Planning for Transit." Transportation Research Record: Journal of the Transportation Research Board 1747 (1): 60-67. https://doi.org/ $\underline{10.3141 / 1747-08 .}$.

Limtanakool, N., M. Dijst, and T. Schwanen. 2006. "The Influence of Socioeconomic Characteristics, Land Use and Travel Time Considerations on Mode Choice for Medium- and Longer-Distance Trips." Journal of Transport Geography 14 (5): 327-41. https://doi.org/10.1016/ j.jtrangeo.2005.06.004.

Mandel, B., M. Gaudry, and W. Rothengatter. 1997. "A Disaggregate Box-Cox Logit Mode Choice Model of Intercity Passenger Travel in Germany and Its Implications for High-Speed Rail Demand Forecasts." The Annals of Regional Science 31 (2): 99-120. https://doi.org/10.1007/ $\underline{\mathrm{s} 001680050041 .}$.

Milligan, Glenn W. 1996. "Clustering Validation: Results and Implications for Applied Analyses." In Clustering and Classification, 341-75. Singapore: World Scientific. https://doi.org/10.1142/ 9789812832153_0010.

Mooi, E., and M. Sarstedt. 2011. “A Concise Guide to Market Research Chapter 8.” SpringerVerlag Berlin Heidelberg.

Morrison, S.A., and C. Winston. 1985. "An Econometric Analysis of the Demand for Intercity Passenger Transportation." In Research in Transportation Economics: A Research Annual, edited by T.E. Keeler, 2:213-237,. Greenwich, Connecticut: JAI Press.

Posse, C. 1998. "Hierarchical Model-Based Clustering for Large Data Sets.” Technical report,. University of Minnesota, School of Statistics.

Punj, Girish, and David W. Stewart. 1983. "Cluster Analysis in Marketing Research: Review and Suggestions for Application.” Journal of Marketing Research 20 (2): 134-48. https://doi.org/ $\underline{10.1177 / 002224378302000204 .}$

Roxas, Nicannor R. 2016. "Application of Artificial Neural Network to Trip Attraction of Condominiums in Metro Manila".” In Proceedings of the 23rd Annual Conference of the Transportation Science Society of the Philippines. Quezon City, Philippines: TSSP. 
Sarkar, Amrita. 2012. "Application of Fuzzy Logic in Transport Planning." International Journal on Soft Computing (IJSC) 3 (2): 1-21. https://doi.org/10.5121/ijsc.2012.3201.

Statistics Canada. 2017a. "Labour Force Survey.” https://www150.statcan.gc.ca/n1/dailyquotidien/180105/dq180105a-eng.htm.

- - . 2017b. "Travel Survey of Residents of Canada." https://www.statcan.gc.ca/eng/survey/ household/3810.

Tharwat, O.S. 2014. "Identification of Uncertain Nonlinear MIMO Spacecraft Systems Using Coactive Neuro Fuzzy Inference System (CANFIS).” International Journal of Control, Automation, and Systems Vol. 3 (2).

Travel Demand Modelling. 2016. "Transport and Infrastructure Council, National Guidelines for Transport System Management in Australia." https://ngtsmguidelines.files.wordpress.com/2014/ 08/ngtsm2016-t1_travel_demand_modelling.pdf.

Wardman, M., J. P. Toner, and G. A. Whelan. 1997. "Interactions between Rail and Car in the Inter-Urban Leisure Travel Market in Great Britain." Journal of Transport Economics and Policy 31 (2): $163-81$.

Yaldi et al. n.d. "Developing a Fuzzy-Neuro Model for Travel Demand Modelling."

Zadeh, L.A. 1965. "Fuzzy Sets." Information and Control 8 (3): 338-53. https://doi.org/10.1016/ s0019-9958(65)90241-x.

Zaki, Mohammed J., and Wagner Meira, Jr. 2014. Data Mining and Analysis: Fundamental Concepts and Algorithms. New York, NY: Cambridge University Press. https://doi.org/10.1017/ cbo9780511810114. 